\title{
HIGH WISDOM INTELLIGENCE - DISCUSSING EDUCATION OF HIGH WISDOM INTELLIGENCE
}

Wen Ma*

Mount Saint Vincent University, Canada.

\section{A R T I C L E I N F O}

Article history
Received 13 January 2020
Revised 14 February 2020
Accepted 17 February 2020

\section{Keywords}

Wisdom intelligence

Nature

society

life

innovation

creation

\section{A B S T R A C T}

The number of talented persons who are equipped with high wisdom intelligence will immediately determine the quality of humankind's entire life, and the future trend for humankind's innovation and creation in fields such as thinking, cognition, society, politics, economy, military, science, arts, culture, and so on. Meanwhile, it protects the harmonious development of various fields. By illustrating the meanings of applying high wisdom intelligence in the survival and prosperity for each nation, ethnicity and individual, this article has a significant application to the understanding of educational studies of high wisdom intelligence.

Corresponding Author: Wen Ma

Email:wen.ma@queensu.ca

(C) The Author(s) 2019.

\section{INTRODUCTION}

The most popular intelligences (quotients) in the world such as intelligence quotient, emotional intelligence, moral intelligence, mental health intelligence, literacy intelligence, motivation intelligence, aesthetic intelligence, legal intelligence, food intelligence etc. - are greatly related to wisdom intelligence (wisdom quotient). Wisdom intelligence is the fundamental intelligence of multiple intelligences. It is the soul and root source of multiple intelligences.

When it comes to the level of understanding about nature, universe, society, life and heart, the high wisdom intelligence that an individual owns can be holistic, profound, and thorough (Ma, 2017). A person with high wisdom intelligence is not confused about anything. In the process of someone's life journey, she/he demonstrates a powerful autonomous spirit to innovate and an ability to create.
Humankind is calling for education of high wisdom intelligence, and the return to education of high wisdom intelligence. Thousands of years of human history indicate that humankind's innovative spirit and creative ability come from the educational studies of high wisdom intelligence; humankind's civilized prosperity comes from educational studies of high wisdom intelligence. Humankind's future hope is rooted in educational studies of high wisdom intelligence, and the root of humankind's material development and the soul of culture prosperity are within educational studies of high wisdom intelligence. The number of talented persons who are equipped with high wisdom intelligence will immediately determine the quality of humankind's entire life, and the future trend for humankind's innovation and creation in fields such as thinking, cognition, society, politics, economy, military, science, arts, culture, and so on. Meanwhile, it protects 
the harmonious development of various fields. Most importantly, it is the positive energy in relation to the survival and prosperity for each nation, ethnicity and individual. Its significance is mainly illustrated as follows.

FIRST, TO BE INSISTENT IN APPLYING HIGH WISDOM INTELLIGENCE IN AUTONOMOUS INNOVATION AND CREATION STRONGLY ASSURES THE REALIZATION OF PEACE AND DEVELOPMENT OF THE WORLD AND HAPPINESS OF HUMANKIND.

Without humankind's innovative spirit and creative ability, prosperous world development, humankind's genuine peace and authentic contentment do not exist. The innovative spirit and creative ability do not separate from the discovery, mastery and application of high wisdom intelligence. Thus, applying high wisdom intelligence to autonomous innovation and creation powerfully assurances the peaceful development of the world and contentment of humankind.

In today's world, the server natural crisis has been threatening the lives of humankind at all times; especially, the climate and environmental problems in nature have caused humankind to suffer even more than the wars (Reynolds, 2006). Why do these problems occur? Despite the unavoidable factors such as natural disasters, the main reason is due to the absence of high wisdom intelligence education.

\section{Issues of climate change}

More and more carbon dioxide has been released into the air, so the damage to the ozone layer is worsening (Reynolds, 2006). These phenomenon has caused the greenhouse effect. Global warming has let the melting of ice sheets that covers the surface of the earth and eventually will result in the disappearance of coastal areas. Global warming will produce a great impact on humankind's ecological environment and standard of life, even disastrous consequences.

\section{Issues of water crisis}

Currently, there is only $1 \%$ of water resource in the world can be used for human supply. In the near future, water scarcity led by rivers drying up will turn into a serious social crisis (Vörösmarty et al., 2010).

\section{Issues of extinction of species}

In today's world, the earth has been experiencing the sixth mass extinctions and resulting in the degradation of the ecological system (Hutson, Law, \& Lewis, 1985).
Because the pollution and destruction humankind has made to our eco-environment, genetic resources, and the massive killing of wild animals and plant life have been going through a great calamity. The number of wild animals that are on the edge of extinction has been increasing. These phenomena will become a human tragedy. Species lay the foundation of the production of the organism and the development of the social economy. Thus, the disappearance of species will generate a great impact on the survival of humankind (Myers, 1976). The human-made extinction served as a warning sign: human extinction is happening.

\section{Issues of land degradation}

Humankind's mass destruction to forests has directly affected the occurrence of phenomenon such as floods, water and land degradation, soil erosion, heavy rainfall, steep slopes, sea-level rise, and the decreasing of reservoir capacity (Sabatier et al., 2014).

\section{Issues of eco-safety}

Due to the degradation of eco-system, grassland vegetation has been severely damaged (Poulenard et al. 2014). Desertification and dry areas of land have become an ecological safety concern at a national level. Statistics show that deserts on earth has been rampantly depleting lands on a speed of 600 thousand hectares per year. In other words, 10 hectares of land is disappearing per minute. Currently, the frequent attack of sand storms indicates one of the serious consequence that desertification has produced.

\section{Issues of deforestation}

Human activities such as the conversion of treasurable forestland to farms, ranches, urban areas use, or the exchange to foreign currencies has caused 12,000,000hectare forest disappearing each year (Munson, Belnap, \& Okin, 2011).

\section{Issues of acid rain}

As a result of the development of global industrialization and the rapid increase of population, human demand for petrochemical fuel has greatly grown (Abelson, 1983). Acid rain pollution produces severely harmful effects on agricultural products and plants, and lead to adverse impacts on the balance of the ecological system and the disappearance of forests on a massive scale.

\section{Issues of waste disposal}

The rapid increase of global industrial household wastes has become a shared problem of all nations (Powell, 2002). A large number of wastes cannot be disposed of. Occupying cultivated land to destroy or bury material 
wastes is a common phenomenon. Air and underground water have been infiltrated by waste. Numerous cities in the world have been turned into waste deposits.

\section{Issues of urban air pollution}

The main resource of coal in urban areas can release a range of toxins (Agrawal, Singh, Ribeiro, \& Delgass, 2007). More and more traffic-related emissions pollute the air and expose residents of cities to harmful air. The air quality of many cities is lower than the national standards.

All the phenomena mentioned above are due to the absence of high wisdom intelligence education. Being distant from high wisdom intelligence results in a foolish state of low wisdom intelligence. This explains the reason why the phenomenon of disobeying natural laws is happening everywhere. The severe damages are irreversible. It is undeniable that humankind cannot prevent normal natural disasters from happening. It does not change according to humankind's wills. Yet, when we think about the cause of the above-mentioned phenomenon, we cannot help but wonder: which one is not a human-made disaster? When facing the objective world, without the guidance of high wisdom intelligence, we will ultimately forget the fundamental meaning of human life. We do not know how to live with nature in harmony, do not respect nature, do not follow nature, do not obey natural laws; instead, we have remained a captive to our immediate interests, caught up in the mud of narrow-minded utilitarianism, and blindly choose to pursue our own benefits.

When discussing various social issues, what does humankind do? In comparison to the past centuries, all types of complex social issues in the new century have become more and more serious. Despite the fact that humankind has obtained great accomplishments in areas of technological advancement, economic growth and cultural prosperity, humankind's low wisdom intelligence have brought many disasters and vices to the international community.

\section{Issues of the global economy}

Currently, the level of interdependence within the global financial system has surpassed that any of periods of history (Hausman \& Johnston, 2014). It is claimed that the major bank within a specific nation or a financial crisis in a specific area can influence the whole world. For example, the global financial crisis in 2008 resulted in the most severe global financial decline since the Great Depression (Ivashina \& Scharfstein, 2010).

\section{Issues of the spread of weapons of mass destruction}

To use competitive technology to produce and spread a weapon of mass destruction has been considered a significant issue in the current international community (Stokstad, 2003). Certain nations violate all the standards and principles established in international law and human rights and continue to use and spread these weapons. Their acts have greatly threatened international peace and safety.

\section{Issues of ethnonational conflicts}

Wars among nations are constant. The problems of conflict of ethnicity and nationalism are obvious and salient. These issues are contributing to the destruction of harmony in humankind's homes and are becoming a threat to humankind.

\section{Issues of human life resource scarcity}

As the food and energy prices of the world reaching sky high, resources for the survival of humankind are becoming seriously scarce (Beshir, 2018). Each year, forty thousand children die from malnutrition and related illnesses. Because of the food shortage, 1.5 billion children are suffering from starvation. Poverty is considered one of the worst global issues (Squicciarini, Guariso, \& Swinnen, 2013).

What is mentioned above is a potential crisis of humankind. The cause of them is due to the low wisdom intelligence of humankind. What do we need to save the crisis of humankind? As far as I am concerned, all types of natural disasters and social crisis result from the foolishness of humankind. Only by having of and carrying out high wisdom intelligence education can humankind be saved. When ethnicity and a nation insist and practice high wisdom intelligence education, the citizens of this nation will be led by high wisdom intelligence. They will take initiative to cultivate their mind and body; there will be friendliness and care among people; there will be interdependence among ethnicities; there will be cooperation among nations; there will be peace within humankind; there will be stability within society, and there will be contentment within each individual. At this time, the crisis will be eliminated.

High wisdom intelligence education is an ultimate education that reconciles the multiple crises among nature, nations, families and individuals. The global home is a whole entity. Only through each individual part developing naturally and harmoniously can positive energy revive. A nation is a whole entity. Only through 
each individual part developing naturally and harmoniously can it be safe and peaceful. An individual is also a whole entity. Only through each individual part developing naturally and harmoniously can she/he possess authentic happiness. When encountering all types of crisis in nature, nations, society and individuals, have you realized that we have been disobeying the natural universe's laws of development because our humankind has lost high wisdom intelligence education for a long period time. How could we not be punished?

Let us to be insistent of high wisdom intelligence education! Let us to practice high wisdom intelligence education! Let us to spread high wisdom intelligence education! Only after being equipped with high wisdom intelligence can humankind truly save the crisis of the world.

\section{SECOND, TO BE INSISTENT IN APPLYING HIGH WISDOM INTELLIGENCE IN AUTONOMOUS INNOVATION AND CREATION STRONGLY ASSURES A NATION'S PROSPERITY.}

When facing the severe challenge of competition among nations and the survival of humankind's environment in the $21^{\text {st }}$ century, living in the current knowledgeeconomy society featuring high technology, we shall possess an innovative spirit and creative ability. The high wisdom intelligence that each one of us has during the process of learning, mastering and applying subjects of knowledge determines a nation's speed for development, which, in turn, raises higher and more holistic demand for the education of humankind. Besides the mere task of delivering knowledge, school education shall actively explore and carry out high wisdom intelligence education that centres on the discovery of each individual's innovative spirit and creative ability (Kranzler, 1997). This is the demand of $21^{\text {st }}$ century and the calling of humankind - it calls the education around the world to return to its genuine educational ideals; it calls the innovation and development of educational ideals - a completely novel educational ideal - for humankind; it calls society to explore and carry out high wisdom intelligence education that is appropriate to the epoch's demand and development. Meanwhile, we nurture talented people with holistic moral disposition, broad scientific knowledge and balance in mind and body - talents with high wisdom intelligence.

To actively explore and practice high wisdom intelligence education sets the premises for the establishment of an innovative country. In today's world, pioneering educational ideals tend to overemphasize individuals' knowledge accumulation rather than focusing on the cultivation of the innovative spirit and creative ability. The main focus of school education on cognitive development has led the mastery and application of an innovative way of thinking being neglected (Decker, Hale, \& Flanagan, 2013). In the process of schooling, there still exists rote learning and memorization, using text scores to evaluate an individuals' quality; there is a severe separation between learning and practice; and severe disengagement between mind work and hands-on experience (Carter, 1998). Students under these types of educational models demonstrate a state of high grades and low wisdom intelligence. They show weak abilities to analyze, master and solve practical problems; and lack in innovative spirit and creative ability to actively explore (Della-Piana 2008). The results of merely focusing on cognitive education are the production of mechanical beings who are strong in knowledge learning but lack the ability to adapt to the life of society (Fowler, 2008). How can this educational condition match the goal of building an innovative nation? An educational institution that an innovative country demands should be depicted with the following criteria: this institution is established on the basis of high wisdom intelligence education; this institution shall evaluate students with a comprehensive set of standards; this institution shall cultivate and inspire students to perfectly combine learning and practicing and to holistically combine mind-work and hands on experience; this institution shall encourage students to develop innovative imagination and divergent way of thinking; this institution shall encourage students to take risks and actions; this institution shall also nurture students' abilities of independent thinking and problem-solving skills. This type of institution of high wisdom intelligence requires holistic development and is persistent in spreading high wisdom intelligence. Only under the guidance of this educational institution can students become talented individuals of overall development and powerful innovative spirit and creative ability. The talented individuals that an innovative nation demands shall be depicted with the following standards. In practice, high wisdom intelligence plays a role in their survival. Their ways of thinking are holistic and sensible. They are 
equipped with a spirit of action: they dare to think and to act. They respect teamwork such as cooperation and collaboration. Their ability to independently complete tasks and solves problems is strong. They can not only autonomously master comprehensive knowledge but also independently apply them into practice. These characteristics illustrate talented individuals with high wisdom intelligence that the establishment of an innovative country truly needs, and the high wisdom intelligence education should aim at.

The establishment of an innovative nation does not separate from talented individuals with high wisdom intelligence. Yet, the current educational model overemphasizes cognitive education and ignores high wisdom intelligence. As a result, it can hardly bear the task. It is even more difficult to serve as the strategic support for the improvement of social productivity and a comprehensive national strength (Foray \& Raffo, 2014). We have to admit that our current education has achieved improving performance in terms of autonomous innovation (Fischman \& Gandin, 2016). Yet, due to the long-term absence of high wisdom intelligence education, many people have low wisdom intelligence. Individuals' autonomous innovative abilities are weak (Thomas, Strage, \& Curley, 1988). Many of them lack in the spirit of action-taking and passively accept new phenomenon (Chuang 2008); Their activities of independent creation and imaginative abilities are scarce; inventive senses are indifferent, and the ways of thinking are rigid. When becoming familiar with their own logical way of thinking, analyzing, synthesising, theorizing, and hypothesizing, they are afraid to take risks. Moreover, because their inventive abilities are so scarce, students cannot meet the practical needs of independent creation and invention (Fischman \& Gandin, 2016). Collective and individual patent on inventions is still lagging behind the demand for establishing an innovative country. The fruits of autonomous innovation and creation are not satisfying (Noor \& Crossley, 2013).

Due to the absence of high wisdom intelligence education, the model of cognitive education still plays a major role. Individuals are not equipped with genuine abilities to autonomously innovate and create. Thus, in life or at work, unhealthy tendencies exist (Zacher \& Wilden, 2014). For example, academic plagiarism (Lewis, Duchac, \& Douglas Beets, 2011), fake and forged commodity (Bevan 2010), and hypocritical and deceitful interrelationships. In a team-work environment, people are jealous of and cynical about those who dare to innovate and invent (Takaku, Weiner, \& Ohbuchi, 2001). Some leaders do not like those with a strong innovative spirit. These foolish activities, which resulted from low wisdom intelligence, are against the demand of establishing an innovative nation. The existence of the outdated phenomenon is the main reason why innovative talents are greatly lacking and innovative and creative products are few.

THIRD, TO BE INSISTENT IN APPLYING HIGH WISDOM INTELLIGENCE IN AUTONOMOUS INNOVATION AND CREATION STRONGLY ASSURES THE NATION'S DEVELOPMENT.

Only high wisdom intelligence can guarantee the genuine execution of autonomous innovation and creation. Only high wisdom intelligence serves as the most efficient energy for the nation's development.

With the application of high wisdom intelligence, Canada has contributed to the task of developing innovation and creativity of humankind (Nicol, 1965). Today, only through applying high wisdom intelligence to discover, innovate and create can Canada grow and develop. In terms of the areas of affairs of society that are outdated or need improvement, we shall get rid of the stale and take in the fresh. In terms of those areas of affairs of society that are small and weak, yet have the potential for development, we shall provide support for it to thrive. In terms of those areas of affairs of society that is stray away from the objectives or excessively over planning, we shall creatively adjust them. Which of these above-mentioned acts separate from people's discovery, mastery and application of high wisdom intelligence?

The primary issue for national growth is to develop strong ethics and human values because it assures the original incentive for national development (Christie, 2002). Second, economic growth serves as the base of Canadian development. Only economic growth that focuses on both the results and process of innovatively deliberating and creatively developing productivity can provide sustainable material support for the nation's advancement (Hayter \& Barnes, 2001). Third, cultural development is the foundation of Canada's national development. A culture such as political culture, economic culture, civil culture, human culture, etc. awaits to develop innovatively and creatively include 
(Braz, 2016). Fourth, the simultaneous development of both the nation and its citizen is the heartbeat of Canada's national development (Bruning, 2010). Only by allowing citizens to share the material and spiritual fruits of national development can they join forces, strive collectively, and become the living energy for Canada's ethnical and national development. Finally, military development is the safeguard of Canada's ethnical and national development (Nevitte, 2002). Which of these acts separate from people's discovery, mastery and application of high wisdom intelligence?

The ethical progress is to centre on the development of innovation and creation in core areas such as the nation's essential values, economy, culture, nation and its own people, military, etc (Dupré, 1993). By carrying out strategic plans such as removing the out-dated business, recognizing, restoring, accelerating growth, Canada will ultimately maintain its status in the world. The development of these fields demands continuously enhance the innovative spirit and discovering creative abilities (Nevitte, 2002). What is also needed is the support of Canadian values as well as the foundation of high wisdom intelligence education. Which one of these acts separates from people's discovery, mastery and application of high wisdom intelligence?

The generation and development of ethical values are closely related to autonomous innovation and creation (Panofsky, 2018). High wisdom intelligence at different periods of time produces different ethical values. High wisdom intelligence in ancient Greece created values of wisdom, courage, discipline and justice. High wisdom intelligence in contemporary France created values of freedom, equity and love (Johnstone, 2009). The spirit of high wisdom intelligence is transformed into ethical values in the Western land (Hale, 1996).

The root of Canadian ethical values is the application of high wisdom intelligence. Canadian ethical values are shaped by their developing process. It reflects the lives of Canadian with multicultural backgrounds and represents Canada's wise culture. It is the formation of people with different cultural backgrounds and their worldviews, life views, ideals and beliefs. It is the moral support for Canadians' survival and abilities to thrive (Taylor, 2004). This is the soul of high wisdom intelligence culture.

High wisdom intelligence values that Canada gradually forged are centred on peace, compassion, respect, to be there for each other, and to search for equality and justice. And the fundamental reason for its formation and development is the application of high wisdom intelligence. They are forged by the positive energy of high wisdom intelligence. The essence of Canadian values is abundant (Christie, 2002). For instance, the value of patriotism that is shaped through social practices; the value of maintaining peace, equity, friendliness, collaboration while dealing with other nations; the value of willingness to work hard that Canadians demonstrate while changing the practical world; the value of respect as the result of Canada respecting its citizens' wills, wisdom and power into account in order to achieve its shared aim; the value of equality that is demonstrated as honesty, credibility and keeping promises; the value of service; and the value of learning and being respectful of science (Hehner, 1999). The base of these values is the application of Canada's high wisdom intelligence. They are the active exercises of Canada's high wisdom intelligence.

Ethnicity is a cultural concept. The root of the ethnicity is thinking, culture and values (Ferguson, 1966). In other words, the flag of a nation represents its ethical values (Hutcheson, 2015). The liveliness of a nation's ethical value comes from the succeeding and spreading of high wisdom intelligence. To succeed and spread ethical values is to solve the problem between inheritance and innovation. Succeeding ethical values is the main task. Innovation is the root to succeed and spread ethical values. Innovation with high wisdom intelligence has the fundamental power to succeed and spread ethical values. The existence and increase of a nation's ethical values are not just to reinforce those of the past. To genuinely succeed and develop, we can only innovate and create an ethical culture with high wisdom intelligence so that ethical values can be infinite. Thus, Canadian ethical values are an up-to-date affair; they continuously grow and strive. History tells us, that during each time period of revolution, establishment and reformation of our nation, as long as we do not cease innovation and creation with high wisdom intelligence, there will be the production of ethical values that advance with the times. Insistently to apply autonomous innovation and creation with high wisdom intelligence strongly assures Canada's development.

FOURTH, TO BE INSISTENT IN APPLYING HIGH WISDOM INTELLIGENCE IN AUTONOMOUS INNOVATION AND CREATION STRONGLY REASSURES 


\section{ALL CITIZEN'S SAFETY AND HAPPINESS.}

The aim of Canada's national progress is to fulfil, maintain, and develop the fundamental benefits of all citizens and improve the index of their life quality. The index of life quality consists of both material and nonmaterial factors (Braz, 2016). Fundamentally, it is to further enhance the level of social stability. The enhancement of social stability does not separate from the improvement of each individual's high wisdom intelligence.

The practical foundation of Canada's national development lies in science and technology. Its theoretical base lies in ethics. Its foundation of incentive is to continuously enhance people's wellbeing (Nicol, 1965). For hundreds of years, Canada thoroughly insists on the discovery, mastery and application of high wisdom intelligence to autonomously innovate and create happiness. Canada thoroughly insists on the following beliefs: as long as we hold a blueprint of high wisdom intelligence, our dream will come true. As long as we keep pursuing goodness, the wonderful moral culture will be realized; as long as we engage in innovative and creative practices, an abundant material culture will be fulfilled (Parks, Joireman, \& Van Lange, 2013).

The process of globalization by which each nation is undergoing intense competition will eventually become the competition for talented individuals with high wisdom intelligence. This is an inevitable result led by the law of technology serving as the first productive force (Hayter \& Barnes, 2001). Practices show that the economic prosperity in a nation or an area is not determined by its productive force, rather, it is determined by the level of its individual's wisdom intelligence. Education of high wisdom intelligence plays a determent role in nations' economic competitiveness in the future. The practice of high wisdom intelligence education is the education with the capital "E". It enhances citizens' overall quality and enlightens citizens' innovative spirit and creative ability.

The issue of Canadians obtaining their wellbeing is beyond the scope of this paper. Wellbeing is the selfevaluation and reflection that people make toward their quality of life (Yasuhiro \& Koyasu, 2012). Research shows that people's wellbeing is a project with a complex system (Kammann, Farry, \& Herbison, 1984). It is closely related to natural environment, harmonious and stable social environment, positive moral environment, peaceful relational environment, advanced cultural environment, consummate political system, excellent culture of tradition, legalized religious belief and practice, equalized income distribution, ideal benefits system, employments that allow individuals' talents, and complete public services, etc. (Braz, 2016; Miles \& Rossi, 2007).

Bhutan came up with an internationally accepted standard of Gross National Happiness (GNH). It is equally acknowledged as Gross Domestic Product (GDP). Gross National Happiness explains to us that the issue of fundamental survival is to maintain a balance between material life and non-material life. GNH is more vital than GDP. This index mainly consists of a citizen's psychological well-being, happiness, cultural life, health, etc (Lepeley, 2017). It tells us that, harmony between material and non-material life serves as the authentic standard to improve the happiness of citizens (Ferguson, 1966). We cannot solely rely on the economy to enhance people's happiness (Melnick, 2014). The most fundamental idea is to insistent on high wisdom intelligence to enlighten people's innovative spirit and creative ability; to enhance citizens' discovery, mastery and application of high wisdom intelligence, to improve each individual's high wisdom intelligence, to allow citizens to be equipped with the ability to fulfil their dreams, and to truly achieve the balance between material and non-material life.

There is no smooth path for Canada to achieve its objectives. To break the barriers and to obtain citizen's happiness relies on education of high wisdom intelligence. The growth of the economy is urgent. The task of filling the economic gap and diminishing poverty is difficult. The call for environmental changes such as eliminating air pollution indicates the hardship of shifts of productivity model and life habits. Higher standards are demanded government institutes to provide peopleoriented public services and to establish citizens' interest-driven policies. These are all concerns relating to the citizens' quality of life index and are shall not be neglected (Nevitte, 2002).

Canada's achievements of its objectives aimed at the growth of the economy, promotion of social equality and justice, and increase of Canadian's wellbeing (Hehner, 1999). The fulfilment of Canadian's wellbeing must be established on the basis of high wisdom intelligence education and the steady steps it shall take. The 
objective is a collective one. The realization of the aim is not the realization of an individual, but Canada as a whole. Thus, the fulfilment of Canadian objectives depends on the discovery, mastery and application of its citizens' high wisdom intelligence; and on the insistence and spread of education of high wisdom intelligence. To enlighten people to autonomously innovate and create strongly reassures its citizens' happiness and safety.

FIFTH, TO BE INSISTENT IN APPLYING HIGH WISDOM INTELLIGENCE IN AUTONOMOUS INNOVATION AND CREATION STRONGLY REASSURES EACH INDIVIDUALS' PEACEFUL LIFE.

If one is asked, "where is knowledge?" the answer is "knowledge is in mind, mouth and texts." If he is asked again, "where does knowledge come from?" The answer is "knowledge comes from texts." or "knowledge comes from others." If the person is asked again "where does the knowledge of the person who wrote the first book come from?", a problem occurs. When people have no texts to learn from, and no people to ask, this person's cognitive activities temporarily stop - remember, it is "temporary". But I know, many people in the contemporary world are living in such a state of being (Baehr, 2016). Because their lives cannot separate from books or obtaining knowledge from others, humankind's innovative spirit and creative ability are not near to them (Hanse, 2007). Thus, his/her life will be filled with countless problems. All sorts of pain and annoyance will come to disturb them from time to time. How could he/she live in the realm of peace and happiness?

As far as I am concerned, the key of all types of learning activities has nothing to do with learning something; rather it is the issue of why we learn, how to learn and how to apply knowledge (Kristjánsson, 2016). In other words, how is it to understand and experience the truth of knowledge production and let high wisdom intelligence genuinely lead the practice. In life we often observe some people who can talk about knowledge; yet in early life, especially when encountering life challenges, they demonstrate high intelligence and low wisdom. How can these types of people discover, master and apply high wisdom intelligence to autonomously innovate and create? How could they lead a peaceful and happy life?

What has caused these abnormal phenomena to happen? The reason is closely related to the education that is lacking innovative and creative wisdom intelligence on a global scale. It is also directly associated with outdated educational ideals (Hanse, 2007) Every time I see so few people walking into university entrances to accept higher education, I wonder, what about those who were not admitted? Is his/her opportunity for education stopped at that moment? Every time I notice a large number of graduates leaving schools, I also wonder, are their opportunities to be educated stop at this moment? The reform of school education has achieved great progress. Although educational ideals and methods remain problematic, this achievement cannot be eliminated. Yet what I am talking about here is the major educational issue at the societal level - the main issue in relation to life-long learning that our nation, society and people urgently need. The nature of the issue has to be concerned with where the function of education is located. The grand education offered to people does not refer to merely narrow cognitive education; rather, it shall serve to enhance the holistic quality of humankind's mind and body; and shall be based on high wisdom intelligence. This is the high wisdom intelligence education that I am talking about.

Where did the liveliness of innovative spirit and creative abilities that humankind possesses disappear to (Shields, 2011)? How many people's innovative spirit and creative abilities are oppressed and eliminated each day (Lewis et al., 2011)? Has humankind become more intelligent or foolish (Baehr, 2016)? In the educational environment, is an innovative spirit and creativity becoming stronger or weaker? The undeniable truth is that as an individual gets older, their time to accept social education, school education and family education is longer; their knowledge is increasing. Yet, what is decreasing is their infinite liveliness and trademarks of their seeds of innovation. A few examples are curiosity, interests to think innovatively, innovative activities, the spirit of inquiry, exploration of innovative learning, question-asking and critical analysis, etc. Psychological problems such as an individual's dependence on others' experiences or book knowledge are becoming salient. These are the educational issues that the society, schools and families should pay close attention to because it is closely linked to the fundamental issues of how an individual should peacefully live in the world, and how a nation and an ethnicity enhance the quality of its citizens.

Why in today's world where technology is greatly 
advanced and life quality is progressed dramatically, there still exists improbable, out-dated, decaying hideous, and foolish social phenomena? The undeniable truth is that it is the consequence of humankind losing their high wisdom intelligence education for a long time. Why has humankind become more distant from high wisdom intelligence? Why has humankind been absent from high wisdom intelligence education? How much attention and investment societies, schools and families have been given to high wisdom intelligence? For a long time, humankind has merely focused on empirical discussion and research and has forgotten the discussion and research in relation to high wisdom intelligence and its role in knowledge, experience, emotion, aspiration and thinking. They have forgotten the significant role high wisdom intelligence plays in the process of human life. In other words, to seek and practise utilitarianism on a global scale will inevitably yield mere cognitive educational results in a utilitarian sense (Ben-Eliyahu, Rhodes, \& Scales, 2014). This is why humankind has lost high wisdom intelligence education for the long term. If someone asks: what is missing in the field of education? The answer is that we are missing high wisdom intelligence education that aims at enhancing the life quality of humankind. If someone asks: what should education do? The answer is that to be insistent and carry out high wisdom intelligence education that aims to enhance the mind and body quality of humankind. Thus, to be insistent and carry out high wisdom intelligence education, to enhance each individual's autonomous innovative spirit and creative abilities strongly reassures each individual's peaceful and happy life.

\section{CONCLUSIONS}

To summarize, the roots of human life is tied in with high wisdom intelligence, and the nature of human life is linked to high wisdom intelligence. High wisdom intelligence represents the fountain of human power. It is the fundamental energy to strongly reassures humankind's innovative spirit and creative ability.

Everything in this world has a law to follow. Nature has a law to follow; society has a law to follow; life has a law to follow, and high wisdom intelligence education has a law to follow. As long as we are insistent to discover, master and apply high wisdom intelligence, carrying out high wisdom intelligence within families, schools, societies and individuals, each one of us will be able to reach to the natural, harmonious and happy status in areas such as thinking, working and living and become talented with high wisdom intelligence.

\section{CONFLICT OF INTEREST}

Author(s) declare no conflict of interest.

\section{REFERENCES}

Abelson, P. H. (1983). Acid Rain. Science, 221(4606), 115-115. doi:10.1126/science.221.4606.115

Agrawal, R., Singh, N. R., Ribeiro, F. H., \& Delgass, W. N. (2007). Sustainable fuel for the transportation sector. Proceedings of the National Academy of Sciences of the United States of America, 104(12), 4828-4833. doi:10.1073/pnas.0609921104

Baehr, J. (2016). Is intellectual character growth a realistic educational aim? Journal of Moral Education, 45(2), 117-131. doi:10.1080/03057240.2016.1174676

Ben-Eliyahu, A., Rhodes, J. E., \& Scales, P. (2014). The Interest-Driven Pursuits of 15 Year Olds: "Sparks" and Their Association With Caring Relationships and Developmental Outcomes. Applied Developmental Science, 18(2), 76-89. doi:10.1080/10888691.2014.894414

Beshir, H. (2018). The Impact of Irrigation on Poverty Reduction and Food Security at The Household Level in South Wollo, Ethiopia. Eastern Africa Social Science Research Review, 34(1), 65-107. doi:10.1353/eas.2018.0002

Braz, A. (2016). Canada's Hemisphere: Canadian Culture and the Question of Continental Identity. American Review of Canadian Studies, 46(3), 349-361. doi:10.1080/02722011.2016.1214606

Bruning, E. (2010). A methodological assessment of ten years of Canada's Citizen's First satisfaction survey research. International Review of Administrative Sciences, 76(1), 85-91. doi:10.1177/0020852309361579

Carter, K. (1998). Action research in partnership: establishing teachers as key players. Educational Action Research, 6(2), 275-303. doi:10.1080/09650799800200054

Christie, N. (2002). Households of faith: family, gender, and community in Canada, 1760-1969. Montreal, Canada: McGill-Queen's University Press.

Decker, S. L., Hale, J. B., \& Flanagan, D. P. (2013). PROFESSIONAL PRACTICE ISSUES IN THE 
ASSESSMENT OF COGNITIVE FUNCTIONING FOR EDUCATIONAL APPLICATIONS. Psychology in the Schools, 50(3), 300-313. doi:10.1002/pits.21675

Dupré, L. (1993). Passage to Modernity: an essay in the hermeneutics of nature and culture. New Haven, Connecticut, USA: Yale University Press.

Ferguson, A. (1966). An essay on the history of civil society. Edinburgh, United Kingdom: Edinburgh University Press.

Fischman, G. E., \& Gandin, L. A. (2016). The pedagogical and ethical legacy of a "successful" educational reform: The Citizen School Project. International Review of Education, 62(1), 63-89. doi:10.1007/s11159-016-9542-0

Foray, D., \& Raffo, J. (2014). The emergence of an educational tool industry: Opportunities and challenges for innovation in education. Research Policy, 43(10), 1707-1715. doi:10.1016/j.respol.2014.07.010

Fowler, Z. (2008). Negotiating the textuality of Further Education: issues of agency and participation. Oxford Review of Education, 34(4), 425-441. doi:10.1080/03054980701683627

Hale, J. R. (1996). The civilization of Europe in the Renaissance. New York: Atheneum; Toronto. Canada: Maxwell Macmillan Canada.

Hanse, D. (2007). Ethical visions of education: philosophies in practice. New York, NY: Teachers College Press.

Hausman, A., \& Johnston, W. J. (2014). The role of innovation in driving the economy: Lessons from the global financial crisis. Journal of Business Research, 67(1), 2720-2726. doi:10.1016/j.jbusres.2013.03.021

Hayter, R., \& Barnes, T. J. (2001). Canada's resource economy. The Canadian Geographer/Le Géographe canadien, 45(1), 36-41. doi:10.1111/j.15410064.2001.tb01165.x

Hehner, B. (1999). The spirit of Canada. Toronto, Canada: Maclcolm Lester Books.

Hutcheson, F. (2015). A System of Moral Philosophy: Cambridge University Press.

Hutson, V., Law, R., \& Lewis, D. (1985). Dynamics of Ecologically Obligate Mutualisms-Effects of Spatial Diffusion on Resilience of the Interacting Species. The American Naturalist, 126(3), 445-449. doi:10.1086/284431

Ivashina, V., \& Scharfstein, D. (2010). Bank lending during the financial crisis of 2008. Journal of Financial Economics, 97(3), 319-338. doi:10.1016/j.jfineco.2009.12.001

Johnstone, C. (2009). Listening to the logos: speech and the coming of wisdom in ancient Greece. Columbia, South Carolina: University of South Caroline Press.

Kammann, R., Farry, M., \& Herbison, P. (1984). The analysis and measurement of happiness as a sense of well-being. Social Indicators Research, 15(2), 91115. doi:10.1007/bf00426282

Kranzler, J. H. (1997). Educational and policy issues related to the use and interpretation of intelligence tests in the schools. School Psychology Review, 26, 152-162.

Kristjánsson, K. (2016). Recent Work on Flourishing as the Aim of Education: A Critical Review. British Journal of Educational Studies, 65(1), 87-107. doi:10.1080/00071005.2016.1182115

Lepeley, M.-T. (2017). Bhutan's Gross National Happiness: An Approach to Human Centred Sustainable Development. South Asian Journal of Human Resources Management, 4(2), 174-184. doi: $10.1177 / 2322093717731634$

Lewis, B. R., Duchac, J. E., \& Douglas Beets, S. (2011). An Academic Publisher's Response to Plagiarism. Journal of Business Ethics, 102(3), 489-506. doi:10.1007/s10551-011-0827-8

Ma, W. (2017). Wisdom intelligence is power, humankind is calling for wisdom intelligence education. International Journal of Educational Studies, $\quad 4(1), \quad 01-04$. doi:10.33687/educ.005.02.2712

Melnick, A. (2014). Happiness, morality, and freedom. Boston, Massachusetts: Brill.

Miles, D., \& Rossi, M. (2007). Learning about one's relative position and subjective well-being. Applied Economics, 39(13), 1711-1718. doi:10.1080/00036840600660721

Munson, S. M., Belnap, J., \& Okin, G. S. (2011). Responses of wind erosion to climate-induced vegetation changes on the Colorado Plateau. Proceedings of the National Academy of Sciences of the United States of America, 108(10), 3854-3859. doi:10.1073/pnas.1014947108

Myers, N. (1976). An Expanded Approach to the Problem of Disappearing Species. Science, 193(4249), 198202. doi:10.1126/science.193.4249.198

Nevitte, N. (2002). Value change and governance in 
Canada. Buffalo, Toronto: University of Toronto Press.

Nicol, E. (1965). History of Canada. Toronto, Canada: Musson Book Co.

Noor, M. A. M., \& Crossley, M. (2013). Educational innovation and the knowledge society: development and issues of the clusters of excellence initiative in Malaysia. Asia Pacific Journal of Education, 33(2), 156-169. doi:10.1080/02188791.2013.780675

Panofsky, E. (2018). Renaissance and Renascences. In Renaissance and Renascences in Western Art (pp. 42-113): Routledge.

Parks, C. D., Joireman, J., \& Van Lange, P. A. M. (2013). Cooperation, Trust, and Antagonism. Psychological Science in the Public Interest, 14(3), 119-165. doi:10.1177/1529100612474436

Powell, K. (2002). Environment: Trash trends. Nature, 419(6910), 891-891. doi:10.1038/419891a

Reynolds, R. W. (2006). Climate Change. Nature, 453, 601-483.

Sabatier, P., Poulenard, J., Fanget, B., Reyss, J.-L., Develle, A.-L., Wilhelm, B., ... Arnaud, F. (2014). Long-term relationships among pesticide applications, mobility, and soil erosion in a vineyard watershed. Proceedings of the National Academy of Sciences of the United States of America, 111(44), 1564715652. doi:10.1073/pnas.1411512111

Shields, D. L. (2011). Character as the Aim of Education. Phi Delta Kappan, 92(8), 48-53. doi:10.1177/003172171109200810

Squicciarini, M. P., Guariso, A., \& Swinnen, J. (2013). Food crisis spurs aid for poverty. Nature, 501, 492-492.

Stokstad, E. (2003). PALEONTOLOGY: Ancient Weapon of Mass Destruction: Methane Gas? Science, 301(5637), 1168a-1168. doi:10.1126/science.301.5637.1168a

Takaku, S., Weiner, B., \& Ohbuchi, K.-I. (2001). A CrossCultural Examination of the Effects of Apology and Perspective Taking on Forgiveness. Journal of Language and Social Psychology, 20(1-2), 144-166. doi:10.1177/0261927x01020001007

Taylor, C. (2004). Modern Social Imaginaries. Durham. Durham, NC: Duke University Press.

Thomas, J. W., Strage, A., \& Curley, R. (1988). Improving Students' Self-Directed Learning: Issues and Guidelines. The Elementary School Journal, 88(3), 313-326. doi:10.1086/461541

Vörösmarty, C. J., McIntyre, P. B., Gessner, M. O., Dudgeon, D., Prusevich, A., Green, P., ... Davies, P. M. (2010). Global threats to human water security and river biodiversity. Nature, 467(7315), 555561. doi:10.1038/nature 09440

Yasuhiro, 0., \& Koyasu, M. (2012). What makes people happy and what makes them unhappy? A crosscultural qualitative study on the sense of happiness. International Journal of Psychology, 47, 225-225.

Zacher, H., \& Wilden, R. G. (2014). A daily diary study on ambidextrous leadership and self-reported employee innovation. Journal of Occupational and Organizational Psychology, 87(4), 813-820. doi:10.1111/joop.12070

Publisher's note: EScience Press remains neutral with regard to jurisdictional claims in published maps and institutional affiliations.

Open Access This article is licensed under a Creative Commons Attribution 4.0 International License, which permits use, sharing, adaptation, distribution and reproduction in any medium or format, as long as you give appropriate credit to the original author(s) and the source, provide a link to the Creative Commons license and indicate if changes were made. The images or other third-party material in this article are included in the article's Creative Commons license, unless indicated otherwise in a credit line to the material. If material is not included in the article's Creative Commons license and your intended use is not permitted by statutory regulation or exceeds the permitted use, you will need to obtain permission directly from the copyright holder. To view a copy of this license, visit http://creativecommons.org/licenses/by/4.0/. 